\title{
The Myth of the Philandering Man and the Crafty Woman
}

\author{
*Diego López Alonso \\ Universidad de Almería, Spain
}

Submission: June 13, 2017; Published: June 22, 2017

*Corresponding author: Diego López Alonso, Universidad de Almería, Deparment of Biology and Geology, 04120 Almería, Spain, Email: dlopez@ual.es

\begin{abstract}
The monogamous human mating system arises from a unique psychological experience (i.e. falling in love), in which both partners make a conscious decision to choose a mate and establish a long-term relationship (a pair bond); this provides both intensive and extensive care for their offspring through most of their life. It is a trait particular to humans and one that generates both wonder and incredulity. A number of scholars, however, support a converse view where monogamy is merely an appearance - they argue that sexual infidelity is rampant with both partners. Nevertheless, on reviewing the evidence, it is clear that the expectations (or predictions) from the extended sexual infidelity hypothesis are not met; instead, the results are compatible with the sexually faithful human pair bond. It is concluded that most human mating behavior is dominated by 'caring and faithful' women and men. A host of other sexual behaviors are present in humans but these are secondary and elicited by infrequent or rare circumstances.
\end{abstract}

Keywords: Human mating system; Marriage; Monogamy; Sexual differentiation; Sexual infidelity; Sperm competition

Abbreviations: EPC: Extra-Pair Copulation; NPR: Non-Paternity Rate; RS: Reproductive Success

\section{Introduction}

Homo sapiens are truly a different species, exhibiting a set of special traits not shared with any other animal species. In particular, many scholars support the view that one of the most conspicuous traits of our own species is the mating system, which is characterized by romantic falling in love [1,2] a mutual choice of partner [3] and a long-term pair-bond relationship [4], usually extended far beyond the weaning stage, frequently lasting past the offspring's puberty. Globally, this reproductive behaviour has no parallel. To be more precise, human male behaviour is quite different to that of males in any other species.

The usual behaviour in most male mammals (primates included), is to 'take the female-and-run'. The standard contribution of male mammals to mating is a brief urgent copulation and a 'little spoon of semen'. Indeed, they have good (evolutionary) reasons for doing this, as we learned from Bateman's fruit flies: a male can multiply its reproductive success by mating with as many females as possible [5]. Devoting his efforts to mating and deserting from care may provide greater reproductive success, always higher than a male devoted to his offspring [6]. The paradoxical behaviour of human males motivates the wonder of primatologist and feminist Shara Blaffer
Hrdy [7]: "He [the man] has the capacity to inseminate a dozen or more females: why should he focus on one to the exclusion of others?" Another author stated that it is "a conundrum" [8]. And some of the most reputed evolutionary psychologists write that man's behaviour is a "mystery" [9].

However, some scholars refute the basis of this argument and negate the premise itself. Instead, they argue that the human mating system is not monogamous at all but merely appears to be. Both pair members, using different mating strategies $[10,11]$, would have a sexual driver prone to infidelity. The human male looks for as many mates as he can (the philandering man), and the human female has a double objective: a genetically-optimal male to provide 'good genes' and a good caring social father to provide food and social support [11]. To arrange these two goals appropriately, the woman would experiment (mostly unconsciously) with a sexual urge for genetically-optimal males on the fertile days of the ovulatory cycle, leaving the infertile period for the social husband - she is acting as the crafty woman [12].

In this scenario the human pair bond would be eroded by rampant sexual infidelity promoted by the polygynous trend 
of men and the concealed sexual agenda of women [10-12]. It was claimed that the combined effects may produce a sexual infidelity frequency of around $50 \%$ and 'cuckoldry' rates of up to $30 \%$ [13]. Subsequently, sexual infidelity would initiate a chain of concatenated events: male competition, sperm competition, sexual (anatomical and psychological) dimorphism, and so on. In continuation, we will discuss if the assumptions and expectations of the hypotheses are meet.

\section{Discussion}

Sexual infidelity rate: In the hunter-gatherer way of life, with the man frequently spending long periods away from the camp, leaving his wife alone surrounded by many other men, there would have been multiple opportunities for infidelity [14]. Therefore, if the trend for infidelity is as strong as predicted, these were favourable circumstances for it to occur. Although it is very difficult to get accurate quantitative data of sexual infidelity amongst extant hunter-gatherer groups, it can be indirectly evaluated from the non-paternity rate (NPR). Such sample populations offer the advantage of having no contraceptive measures that might mask the real frequency of sexual infidelity. If sexual infidelity was such a powerful trend as some scholars suggest, most of the offspring would result from 'cuckoldry'. Marlowe [15] revised a number of previous works reporting 9\% NPR in the Yanomamo, 5\% in the Aka, and $0-2 \%$ in the Ju/'hoansi'. In the most recent study, on the Dogon of Mali, which used more advanced methods, the NPR was 1.8\% [16]. Consequently, in contrast to the expectation of rampant sexual infidelity, the NPR data in extant hunter-gatherer groups are very moderate suggesting that extra-pair copulation (EPC) is not frequent.

Nowadays, most humans live in a hyper social environment, interacting with hundreds of other humans and surrounded by thousands more, the ideal milieu for anonymous and brief sexual encounters. So, what actually happens? In Hite's Report on Male Sexuality [17], based on approximately 7000 anonymous survey results, from pairs with more than 36 years of continued relationship, $70 \%$ of male partners had been involved in some EPC, while $30 \%$ have been strictly sexually faithful. A later study reported that $23-56 \%$ of husbands and $17-25 \%$ of wives engaged in some EPC [18]. In a review of similar studies from the UK, France, Australia, and the USA, Dixson [19] reported that $7-44 \%$ of men and $5-52 \%$ of women admitted engaging in sexual infidelity at sometime during her/his life. Lastly, in a more recent survey, the proportion of recognized infidelity was $13 \%$ of women and $14 \%$ of men [20]. It should be noted that, in these studies, a partner is considered sexually unfaithful after just one EPC.

These studies have not recorded the sexual infidelity frequency per individual. It is likely that the EPC number per individual follows a Poisson distribution; that is to say, with the majority of people engaging in 1 or a few EPCs; the number of individuals then reducing as the EPC number increases. Therefore, the methodology is highly inaccurate in estimating the EPC frequency. The above-mentioned figures should be taken as an upper limit not as an average EPC frequency. With this limitation in mind, EPC frequency seems to be relatively moderate. Most humans seem to engage in no, or very few, EPCs. Indeed, the number of people that maintain full sexual fidelity throughout life is impressive: from $30 \%$ to $95 \%$ (around $85 \%$ in the most recent study).

The 'cuckoldry' rate: Notwithstanding, the above data might be biased towards sexual fidelity because of the usual trend for people to answer surveys in a 'socially expected' way. An unbiased, accurate estimator of sexual infidelity is the NPR; or as it is usually labelled, the 'cuckoldry' rate. Modern molecular genetics techniques are extremely sensitive in detecting when a social father is not the genetic father of a child. There are now a handful of accurate studies on this subject, which provide strong evidence. Traditionally, it has been supposed that the NPR was around $10 \%$ [21]; this has been liberally used as a 'magic' value with no empirical support [22]. In a study of various researchers who support the sexual infidelity hypothesis, wide inter-population differences were found - from 2-10\% NPR [23]. The NPR ranged between 11.8\% (Nueva León, México) and $0.4 \%$ (in a Jewish community); the median from six countries was $1.8 \%$ [19]. In a recent study in Europe, the NPR was $0.9 \%$ [24]. (For a review of many of these works see [22] and [19]. The conclusion of the Anderson review [22] was that the world average might be $3.3 \%$, well below the 'magic' $10 \%$ and nearly ten times lower than the $30 \%$ suggested by Goetz et al. [13]. Some may argue that these NPR estimates are from populations that use contraceptives and thus might be biased toward low values. As commented on before, the NPRs from some extant hunter-gatherer societies were also below $10 \%$; most of them considerably lower than this value.

Sperm competition: This is expected from female sexual infidelity. If we take for granted the evolutionary impact of sperm competition on humans, one would expect big penis and testes in the human male. Some evolutionary psychologists seem to have found them as they expressed surprise (and admiration) when observing the 'big size' of testes and penis in human males [19]. This is the most amazing argument propounded by many evolutionary psychologists because it is not supported by empirical facts. For instance, the macaque species has an average body weight of $8 \mathrm{Kg}$ and testes larger than a man of $70 \mathrm{Kg}$ [19]. Similarly, the human penis is not large or thick in comparison with other primates, or other animal species [19]. Several other facts are contrary to the expectations of sperm competition. The poor quality of human sperm, which contains many aberrant sperm cells, is evidence of a null selective pressure on this trait, i.e. the absence of sperm competition. Other traits are likewise contrary: the low spermatogenesis efficiency, the ejaculation rates, etc. [19]. Moreover, the absence of sperm competition 
could be interpreted as evidence of the minor evolutionary effect of female sexual infidelity, thus reinforcing former arguments.

Sexual differentiation: Increased sexual differentiation in all aspects (anatomy, physiology, and psychology) is another expectation resulting from sexual infidelity. The first formulation of this idea was very emphatic: "There is a female human nature and a male human nature, and these natures are extraordinarily different, [...]" [11].

Anatomy: With regard to anatomy, no one can deny that the human sexes are anatomically well differentiated. The average male is taller and stronger than the average female. However, to put this into perspective, we have to compare with our closest relatives (chimpanzees, bonobos, gorillas and orangutans). The male gorilla is significantly bigger than the female; similarly, this occurs in the orangutan male, and even the chimpanzee and bonobo males are more differentiated from females than human males and females. The evolutionary trend in the specific Homo lineage, after the split from the Pan (chimp/bonobo) lineage, is very significant. The first step was Australopitechus, which exhibited great sexual differentiation yet the next step, Ardipithecus ramidus, already exhibited a significant reduction in sexual differences, a trend that has continued along the evolutionary lineage up to H. Sapiens [25].

Number of mates: This is an expectation resulting from the psychological differentiation of women and men. Symons predicted that one of the consequences of sexual selection in humans would be that "Men have evolved over human evolutionary history a powerful desire for sexual access to a large number of women." [11]. Various evolutionary psychologists found some experimental support [10] for this but when recently checked, the results showed that nearly all men (98.9\%) and women (99.2\%) wished for a single mutual relationship [26]. Sometimes, rich and powerful men are taken as examples for the existence of a psychological trend towards a high number of copulations. The reasoning is that they use their high social status to mate with a lot of women to increase their reproductive success (in terms of the progeny number). Nonetheless, one may argue that the psychological trend is actually towards exclusively possessing many women/wives in order to assure paternity over all the offspring, not to achieve a large number of copulations per se. Conversely, high status men (rock stars, film stars, etc.), who could have as many mates as they like, generally engage in monogamous behaviour, with only a minority being promiscuous.

Mating pair choice: Sexual differentiation should also affect psychological mate preferences. Some of the most pervasive predictions of [11] were that men will develop a preference for beautiful and young females because these traits are signs of fertility; whilst women would choose men with a high social status, because this kind of man can afford the economic and social requirements needed for the offspring and wife. David
Buss and co-workers performed an intensive study of this subject, which showed that men and women are very similar in the preferred traits of their partners [27-29]. Buss [27] literally wrote: "Third, neither earning potential nor physical appearance emerged as the highest rated or ranked characteristic for either sex, even though these characteristics showed large sex differences. [...], suggesting that species-typical mate preferences may be more potent than sex-linked preferences." From a review of similar mate preference studies in the USA, in different years over a 50year time period [30] they found that sexes were, for the most part, identical in mate preferences and that they converged over time. In the latest review study, female beauty was ranked 8th by men and high social status was ranked 11th by women out of 18 ranked features [30].

There have been some works specifically devoted to studying the level of differences between the human sexes $[31,32]$. These works showed that the differences, when present, were minimal. At the behavioural level, the differences between sexes are minimal and very restricted [3]. The conclusions were that both members of a human pairing, rather than facing various critical evolutionary problems, shared one of the most fundamental human evolutionary dilemmas: the survival of their extraordinarily vulnerable and dependent progeny. Therefore, both pair members are very involved in their partnership and share most of the critical evolutionary traits, especially in their minds and in their psychology [31-33].

The extent of marriage: Usually, the pair-bond relationship is formally recognized in terms of marriage under the societal rules of the specific culture. Despite the common complaints associated with marriage, most people actually want (like) to be married [17, 34] and do get married. More than $90 \%$ of people are married at some point during their lives [10]. However, marriage frequently does not extend throughout life as it is dissolved in some kind of divorce. Generally, both the divorced pair members want to re-marry with a new partner. Therefore, the historic endurance of marriage is a strong argument in favour of the psychological adaptation to live in a pair bond. Even people who do not intend to procreate (lesbians and gays) usually live in a pair bond, meaning that they carry an imprint in their brains to prefer living so [35].

As we can see, the factual evidence does not agree with the expectations of the philandering man and the crafty woman hypothesis; rather, it is consistent with the pairbond hypothesis. Evolutionarily speaking, the answer to this controversy concerning the human male depends on whether the reproductive benefits of a caring father outweigh the reproductive cost of renouncing EPC. Recently, we approached this controversy in terms of evolutionary games theory [36]. We modelled a game with two players (a woman and a man) and two strategies ('care-faithful' vs. 'desert-unfaithful'). The computer simulations showed that the 'care' condition was indeed unconditional, for women and for men, in order to be 
evolutionarily successful in most ecological scenarios. Working with a mixed-strategy game ('care-unfaithful'), the winner of the evolutionary game shifted sometimes to the 'care-unfaithful' man, under certain special conditions (a high NPR). The winning woman was always 'care-faithful'.

Our model suggests that caring fathers have enjoyed higher RS than deserting fathers under most ecological conditions over evolutionary time despite the presumed theoretical advantage of the latter. We think that this conundrum occurs by starting from an erroneous assumption: equating the number of mates (or number of copulations) to RS. This reductionism may work in most animal species but it does not fit the special constraints of the human species. In humans, male RS is not limited by mating frequency, or the number of mating pairs, and so on; however, male RS is constrained, firstly by offspring mortality [36], and secondly by the birth intervals [37]. Therefore, the only way to ameliorate male RS in humans is to reduce offspring mortality and shorten the inter-birth intervals. For a male partner, both these outputs are integral to his mission within the pair bond. In other words, a human male may be an exceptional sire but if he is not a caring father to his progeny and a caring husband to his wife, especially during periods of lactation [38], he will be evolutionarily unsuccessful [36] over time.

\section{Conclusion}

The most important evolutionary acquisition, unique to the human lineage, is the big brain. Our large brain size posed many challenges to the evolution of hominids, e.g. accommodating brain development during gestation to the anatomical limits of the parturition channel; providing the required care to the altricial offspring and so on. Only a species capable of making a big brain compatible with the RS could dominate so many environments, from the glacial polar ice to the hot, dry deserts. The human pair bond, which can provide plenty of devoted care to the progeny, is therefore central to human evolutionary success. The human pair bond is founded on the sexual fidelity of both mates. The partners have evolutionarily 'signed an agreement' where the female partner offers paternity confidence and the male partner offers unique care to his progeny and wife. Most of the time this evolutionary arrangement works correctly but it is not a rigid dictate; rather it may be flexibly 'adapted', as with most human behaviour, to current circumstances such as pair-bond dissolution (divorce) and cuckoldry, etc.

\section{References}

1. Fisher $H$ (2000) Lust attraction, attachment: biology and evolution of the three primary emotion systems for mating, reproduction, and parenting. J Sex Educ Ther 28(1): 96-104.

2. Schiefenhövel W (2009) Romantic love. A human universal and possible honest signal. Hum Ontog 3(2): 39-50.

3. Stewart-Williams S, Thomas AG (2013) The ape that thought it was a peacock: Does evolutionary psychology exaggerate human sex differences? PsycholInq 24(3): 137-168.
4. Lovejoy CO (1981) The origin of man. Science 211(4480): 341-350.

5. Bateman A (1948) Intrasexual selection. Heredity 2: 349-368.

6. Trivers RL (1972) Parental investment and sexual selection. In: Stich S (edn) Nat Sel Soc Theory Sel Pap. Robert Trivers, Oxford University Press pp: 65-110.

7. Hrdy SB (1999) The Woman That Never Evolved. Harvard University Press, Cambridge, Massachusetts, USA.

8. Dunbar R (2010) Deacon's dilemma: the problem of pair-bonding in human evolution. Proceeding Br Acad 158: 154-175.

9. Conroy-Beam D, Goetz CD, Buss DM (2015) Why do humans form longterm mateships? An evolutionary game-theoretic model. Adv Exp Soc Psychol 51(1): 1-39.

10. Buss DM, Schmitt DP (1993) Sexual strategies theory: An evolutionary perspective on human mating. Psychol Rev 100(2): 204-232.

11. Symons D (1980) Evolution of Human Oxford University Press, Oxford, UK.

12. Thornhill R, Gangestad SW (2008) The Evolutionary Biology of Human Female Sexuality. Oxford University Press. Oxford, UK.

13. Goetz AT, Shackelford TK (2009) Sexual conflict in humans: evolutionary consequences of asymmetric parental investment and paternity uncertainty. Anim Biol 59(4): 449-456.

14. Benshoof L, Thornhill R (1979) The evolution of monogamy and the loss of estrous in humans. J Soc Biol Struct 2(2): 95-106.

15. Marlowe F (2000) Paternal investment and the human mating system. Behav Processes 51(1): 45-61.

16. Strassmann BI, Kurapati NT, Hug BF (2012) Religion as a means to assure paternity. Proc Natl Acad Sci 109(25): 9781-9785.

17. Hite S (1981) El Informe Hite sobre la Sexualidad Masculina. Plaza, Janés, Barcelona, Spain.

18. Small MF (1992) The evolution of female sexuality and mate selection in humans. Hum Nat 3(2): 133-156.

19. Dixson AF (2009) Sexual Selection and the Human Mating System. Oxford University Press, Oxford, UK.

20. Burchell JL, Ward J (2011) Sex drive, attachment style, relationship status and previous infidelity as predictors of sex differences in romantic jealousy. Pers Individ Dif 51: 657-661.

21. Morell V (1998) A new look at monogamy. Science (80- ) 281(5385): 1982-1983.

22. Anderson KG (2006) How well does paternity confidence match actual paternity? Evidence from worldwide nonpaternity rates. Curr Anthropol 47(3): 513-520.

23. Goetz AT, Shackelford TK, Romero GA, et al. (2008) Punishment, proprietariness, and paternity: Men's violence against women from an evolutionary perspective. Aggress Violent Behav 13: 481-489.

24. Larmuseau MHD, Vanoverbeke J, Van Geystelen A, et al. (2013) Low historical rates of cuckoldry in a Western European human population traced by Y-chromosome and genealogical data. Proc R Soc B Biol Sci 280(1772): 20132400.

25. Lovejoy CO (2009) Reexamining human origins in light of Ardipithecus ramidus. Science 326: 74.

26. Pedersen WC, Putcha-Bhagavatula A, Miller LC (2011) Are men and women really that different? Examining some of sexual strategies theory (SST)'s key assumptions about sex-distinct mating mechanisms. Sex Roles 64: 629-643. 


\section{Psychology and Behavioral Science International Journal}

27. Buss DM (1989) Sex differences in human mate preferences: evolutionary hypotheses tested in 37 cultures. Behav Brain Sci 12 1-49.

28. Buss DM, Barnes M (1986) Preferences in human mate selection. J Pers Soc Psychol 50(3): 559-570.

29. Buss DM (1988) The evolution of human intrasexual competition: Tactics of mate attraction. J PersSocPsychol 54(4): 616-628.

30. Buss DM, Shackelford TK, Kirkpatrick LA, Larsen RJ (2001) A half century of mate preferences: The cultural evolution of values. Psychology 63(2): 491-503.

31. Hyde JS (2005) The gender similarities hypothesis. Am Psychol 60(6): 581-592.

32. Petersen JL, Hyde JS (2011) Gender differences in sexual attitudes and behaviors: A review of meta-analytic results and large datasets. J Sex Res 48(2): 149-165.

This work is licensed under Creative Commons Attribution 4.0 License

DOI: $10.19080 /$ PBSIJ.2017.04.555637
33. Hyde JS (2014) Gender similarities and differences. Annu Rev Psychol 65: 373-398.

34. Hite S (1977) El Informe Hite. Plaza, Janés, Barcelona, Spain.

35. Alonso DL (2014) Biología de la Homosexualidad. Síntesis, Madrid, Spain.

36. Alonso DL, Ortiz-Rodríguez IM (2017) Offspring mortality was a determinant factor in the evolution of paternal investment in humans: An evolutionary game approach. J Theor Biol 419: 44-51.

37. Lloyd EA (2005) The Case of the Female Orgasm. Harvard University Press, Cambridge, Massachusetts, USA.

38. Marlowe FW (2003) A critical period for provisioning by Hadza men. Implications for pair bonding. Evol Hum Behav 24(3): 217-229.

Your next submission with Juniper Publishers will reach you the below assets

- Quality Editorial service

- Swift Peer Review

- Reprints availability

- E-prints Service

- Manuscript Podcast for convenient understanding

- Global attainment for your research

- Manuscript accessibility in different formats

( Pdf, E-pub, Full Text, Audio)

- Unceasing customer service

Track the below URL for one-step submission https://juniperpublishers.com/online-submission.php 